\title{
Beyond SMART? A new framework for goal setting
}

\author{
Trevor Day and Paul Tosey \\ ${ }^{a}$ Learning and Teaching Enhancement Office, University of Bath, Bath, UK \\ ${ }^{b}$ Centre for Management Learning \& Development, University of Surrey, Guildford, \\ $U K$
}

Dr Trevor Day

Learning and Teaching Enhancement Office

University of Bath

Wessex House

Claverton Down

Bath

BA2 7AY

Tel 01225384562

t.day@bath.ac.uk

(Received XX Month Year; final version received XX Month Year)

Acknowledgements

TD wishes to acknowledge the support and encouragement of Kate Bullock, Paul Denley and John Seymour. Both authors thank Mary Deane for commenting on a draft of the manuscript. Part of the article draws substantially upon the original analysis of well-formed outcomes in TD's PhD thesis for the University of Bath 'A study of a small-scale classroom intervention that uses an adapted neurolinguistic programming (NLP) modelling approach.'

Notes on contributors

Trevor Day in a Fellow of the Royal Literary Fund and an Academic Writing Co-ordinator at the University of Bath. He holds a PhD in Education, a secondary/FE teaching qualification (PGCE) and is a Master Practitioner of neuro-linguistic-programming (NLP). His current research interests include: exploring students' experiences and perceptions of their writing development and interpreting them through academic literacies and self-regulation theories; the application of NLP in the teaching and learning of academic writing.

Paul Tosey, $\mathrm{PhD}$ (Bath) is a Senior Lecturer in the School of Management, University of Surrey. He has led a national project on Enquiry-based Learning in Higher Education, and was awarded a National Teaching Fellowship by the Higher Education Academy in 2007. His research interests include organisational learning, transformative learning, especially through coaching, and innovations in phenomenological research methods. He is a Master Practitioner of NLP (1992), and his book `A Critical Appreciation of NLP' (2009, co-author Dr Jane Mathison) is published by Palgrave Macmillan. 


\title{
Beyond SMART? A new framework for goal setting
}

\begin{abstract}
This article extends currently reported theory and practice in the use of learning goals or targets with students in secondary and further education. Goal-setting and actionplanning constructs are employed in personal development plans (PDPs), personal learning plans (PLPs) and are advocated as practice within the English national policy agenda with its focus on personalisation. The paper argues that frameworks widely used for goal setting and action planning by UK educational practitioners, in particular 'SMART' targets or goals, have yet to be rigorously examined in the light of relevant theory and practice. Doing so is important given contemporary emphasis on the dimensions of the learner experience regarded by 'learning to learn' practitioners as underpinning effective learning in the modern classroom. The paper draws from social cognitive theory and achievement goal theory, including Zimmerman's criteria for appropriate goals, to suggest an alternative framework for goal- or target-setting - 'well-formed outcomes', a construct from the field of neurolinguistic programming (NLP). In comparison with SMART targets, the authors argue that well-formed outcomes offer a more rigorous and holistic approach, by taking greater account of the learner's identity, affective dimensions (feelings and emotions), social relations and values, as well as encouraging mental rehearsal.
\end{abstract}

Keywords: action planning, goals, outcomes, targets, mental rehearsal, neurolinguistic programming (NLP) 


\section{Beyond SMART? A new framework for goal setting}

\section{Introduction}

In the secondary and 16-19 education sectors in England and Wales some form of action planning, in which a teacher or tutor sits down with a student and discusses their progress and negotiates learning targets with plans to achieve them, has emerged to become a recognisable feature of teaching practice within the last 25 years. Action planning has its recent origins in initiatives such as records of achievement (Broadfoot 1988) and the Technical and Vocational Education Initiative (TVEI) (Technical and Vocational Education Initiative 1991; Merson 1992). It also features as a strong component in careers guidance (Watts 1992, 1993). It has evolved to find modern expression in a variety of forms, including personal development planning (PDP) (Bullock and Jamieson 1995, 1998) and personal learning planning (PLP) (Bullock and Wikeley 1999, 2004).

Action planning can occur at pivotal decision-making stages in a student's career, such as when making choices about subject options or other forms of progression, or can be practiced at regular intervals across the academic year, conducted by a teacher or personal tutor, with the emphasis on the student's ongoing learning. The interaction can be formal or informal. Typically the process involves a review of the student's current situation, dialogue and negotiation between student and tutor/teacher, and recording of decisions and intentions made, which is hopefully followed by the student's action towards meeting such goals or targets in the weeks and months that follow. At the next meeting, the cycle of review, dialogue and negotiation, recording and action is repeated. All such approaches share in common a dialogue between student and tutor/teacher that seeks to clarify the student's choices, identify goals or targets and plan appropriate action to meet them. 
As to how effective action-planning dialogues might be in influencing a student's learning, this depends on the quality of the relationship between staff member and student, the nature of the contract between them, and the manner in which the dialogue is conducted, which is strongly dependent on the skills and enthusiasm of the staff member (Whiteside 1994; Bullock and Jamieson 1998; Bullock and Wikeley 2004). There is evidence that more measurable effects of action planning are apparent in those in most need of support (Bullock et al. 1996) and that gender may influence the nature of the response to action planning, at least with 13-14 year olds (Bullock and Wikeley 1999). Bullock and Wikeley $(1999,19)$ highlight a wide range of possible responses to such interventions:

At its most effective, it is a process that uses the student-centred dialogue with tutors to promote learning, self-awareness and self-confidence, opportunity awareness and the development of planning skills. At its minimal level, it is an interview that helps individuals select appropriate options at a particular learning or career stage. At its worst, it can be an intrusion into private matters.

The focus of this article is on frameworks used to facilitate the interaction between student and tutor/teacher in an action-planning dialogue, especially as it relates to the identification and negotiation of learning goals or targets. In this article, 'goals' and 'targets' are used synonymously, although some practitioners refer to targets as short-term and goals as longer-term (e.g. Jones and Duckett, 2004). The Oxford English Dictionary $(1989,2010)$ defines a goal as 'The object to which effort or ambition is directed; the destination of a (more or less laborious) journey. ... An end or result towards which behaviour is consciously or unconsciously directed.' A goal thus embodies two features: a description of an intended future state and action towards achieving that future state.

Goal setting often employs the SMART framework (or similar heuristic), in which a goal is commonly designed to be specific, measurable, achievable/agreedupon, realistic and time-based (Doran 1981; Fielding 1999; Wade 2009). The 
construct of SMART goals, targets or objectives appears to have originated in business and management contexts (Doran 1981; Locke and Latham 2002), having evolved from the 'management by objectives' movement (Drucker 1954; Raia 1965). The first published use of a SMART framework is often attributed to Doran (1981), a brief article written by a management consultant for a business audience, which justifies the heuristic in pragmatic terms without reference to earlier literature. The SMART framework has become a popular means of focusing on performance at institutional, departmental, and individual staff and student levels in the English educational system (Fielding, 1999). Yet there has been comparatively little systematic consideration of the validity or conceptual robustness of the SMART framework (e.g. Wade 2009).

When employed with student learners, SMART goals commonly draw upon established principles of good practice from goal-setting theory; that is, according to Locke and Latham (2002), that goals are specific, challenging but realistic, proximal in time, and engage the learner's commitment. For goals to be realisable, learners greatly benefit from formative feedback that informs them of progress towards meeting their goal. Nevertheless, there is a danger that SMART targets can be employed in an instrumental manner, and divorced from students' active engagement and reflection on their practice. Encouraging reflection and offering feedback are considered highly beneficial in order to consciously engage students in their learning (Bullock and Wikeley 2004, 2008). Also highly relevant is the growing recognition among advocates of various constructs of 'learning to learn' (Claxton 1999, 2006; Watkins et al. 2001; James et al. 2006; Watkins and Lodge 2007) of the importance of the affective domain (feelings and emotions) in learning. It is recognised that a student's feelings and emotions may help or hinder their learning, may promote or 
obstruct their attention and their motivation to learn, and they also form part of the fabric of a student's learning in terms of how, and how effectively, they encode experience (e.g. reviews in Claxton 1999, 2005; Blakemore and Frith 2005; Posner and Rothbart 2007; McNeil 2009).

Critical review of SMART and similar frameworks is needed given that students' target-setting is highlighted as recommended practice within 'personalisation' frameworks of the English and Welsh national policy agenda: for example, 'Pupils have regular opportunities to discuss their progress. Teachers actively involve pupils in setting and reviewing their progress towards their targets' (Department for Children, Schools and Families 2008, 16).

\section{Goal setting: theory and practice}

Goal setting has become an active field of research in educational psychology, both in relation to social cognitive theory and self-regulation (Schunk 1989; Zimmerman 2008) and achievement goal theory (e.g. Pintrich 2000; McGregor and Elliot 2002; Wolters 2004; Anderman and Wolters 2006; Murayama and Elliot 2009).

Zimmerman (2008) reviewed evidence in support of the educational value of goal setting in enhancing motivation and academic achievement. Appropriately-set goals direct students' attention to completing tasks, can motivate them to greater effort and persistence in performing tasks that move them towards achieving goals, and can harness helpful affective responses. As for what might be 'appropriate' goals, Zimmerman (2008) draws upon evidence from the testing of goal-setting theory (Locke and Latham 2002) and social cognitive theory (Bandura 1986) to offer eight criteria: goal specificity; their proximity in time; hierarchically organised; congruence 
between goals of self and others; degree of difficulty; self-generated; level of conscious awareness; and whether goals are process- or performance-orientated.

Schunk's early work (1989) established that broad goals, such as 'Do your best', have poor reliability in enhancing academic attainment in comparison to more specific goals, such as 'I intend to raise my test scores in this subject by at least one grade by the end of the term.' This difference arises, at least in part, because progress towards more specific goals is easier to verify (Bandura 1997). This first criterion is closely related to the second, temporal proximity. Other factors aside, it is more effective to monitor progress towards a goal, and gain feedback and act on it, by doing so at short time intervals rather than long. Ideally, goals are 'nested' hierarchically (Zimmerman 2008) so that smaller goals e.g. gaining better scores in weekly tests, support the achievement of a larger goal e.g. raising the score in the endof-term test by a grade. It helps if an individual's goals are aligned with those of significant others in their lives - perhaps peers or family members - or at least are not actively challenged by them.

A fifth criterion is the degree of challenge of the goal. Zimmerman (2008) reviews evidence that suggests that goals that are attainable but challenging best encourage educational achievement. As for Zimmerman's sixth criterion (goals being self-generated), according to Deci and Ryan's (1985) self-determination theory, goals that are self-generated are likely to engender greater commitment, compared to goals that are set by others. This appears to apply providing the self-set goals are realistic. However, in the classroom context, learners are likely to need guidance, both in formulating goals that are realistic and in aligning them, more or less, with curriculum and assessment expectations. Evidence reviewed by Locke and Latham (2002) 
suggests that goals set by or negotiated with others can be accepted, and committed to, if their rationale is reasonable and is explained.

Regarding Zimmerman's (2008) seventh criterion, there is some research evidence that supports encouraging a high degree of conscious awareness when moving towards achieving goals (Locke and Latham 2002), but others argue for low levels of conscious awareness also being effective (Fitzsimons and Bargh 2004).

For the eighth criterion, Zimmerman (2008) reviews evidence as to whether process goals (e.g. developing expertise in structuring essays) are more or less effective than performance goals (e.g. achieving a better grade in a test) in raising academic achievement. Zimmerman's analysis reveals how complex such constructs are in practice. For example, there is interaction between other self-regulatory constructs, such as degree of automaticity (the extent to which elements of a task are carried out efficiently without conscious awareness) and the manner in which strategies are employed in a self-regulatory manner (for example, with selfmonitoring by recording progress towards reaching goals). Individuals are complex, with a cluster of psychological variables that interact within a social context. Making generalisations about whether to encourage process goals or performance goals may have limited utility, because an individual's acceptance of one or other approach depends on context and on a complex interplay of psychological factors within the individual.

Investigators of achievement goal theory propose four kinds of goal orientation (Pintrich 2000; McGregor and Elliot 2002; Wolters 2004; Anderman and Wolters 2006). A student who is mastery-goal orientated focuses on mastering an academic task, making comparisons between past and present performance in order to judge their success at a task. Those who are mastery-avoidance orientated focus on 
thwarting misunderstanding and avoiding not learning as well as they might. Students who are performance-approach orientated seek to demonstrate their prowess relative to others. Performance-avoidance orientated students, on the other hand, wish to avoid being seen as incompetent or less able than their peers.

Some researchers (e.g. Midgeley et al. 1998; Midgeley et al. 2001; Wolters 2004; Anderman and Wolters 2006) also highlight the importance of the environmental context in which goals are set. A mastery-orientated goal structure refers to a classroom environment that emphasises, through policies and practices, the promotion of learning as being valuable for its own sake, that effort to learn is important, that all students are valued, and that with appropriate effort all students can be successful at learning (Midgeley et al. 1998). A performance-orientated goal structure, on the other hand, refers to an environment that emphasises the importance of competition, gaining high grades and demonstrating ability relative to others. The mastery-orientated classroom culture largely accords with that recommended by some leading proponents of 'learning to learn' approaches (Watkins et al. 2001; Claxton 2006; Watkins and Lodge 2007).

Interpreting the evidence for the efficacy of individual goal orientations and particular classroom goal structures is challenging, because of numerous confounding variables among research studies, including different timescales, the nature of examinations that serve as indicators of achievement, other aspects of the prevailing classroom culture, and so on. However, the weight of evidence suggests that positive orientations (orientations towards a goal) are predictors of achievement-relevant indicators such as self-reported effort and persistence (Pintrich 2000; McGregor and Elliot 2002) and are more likely to be associated with academic achievement in terms of test results (Pintrich 2000). This association applies whether individuals are 
mastery- or performance-orientated. Mastery- and performance-avoidance goals, on the other hand, were more likely to be associated with test anxiety, avoiding challenges, not seeking help, and poorer academic achievement. However, few researchers have been able to document a positive correlation between adopting mastery-orientated goals and academic achievement. This lack of support is an area of active investigation and theorising (Anderman and Wolters 2006). On the other hand, many (but not all) researchers have found a positive correlation between performanceorientated goal-setting and academic achievement (e.g. reviews in Wolters 2004; Anderman and Wolters 2006). As for performance-orientated and mastery-orientated classroom cultures, and associations between these and academic achievement, the findings have been very mixed, with some support and refutation for both types of classroom culture (Wolters 2004; Anderman and Wolters 2006). Such mixed findings are a challenge to the promotion of mastery-orientated classroom cultures as advocated by some 'learning to learn' proponents (Watkins et al. 2001; Claxton 2006; Watkins and Lodge 2007).

In conclusion, Zimmerman's (2008) review suggests eight criteria that, with varying degrees of theoretical and empirical support, might guide the appropriate use of goal-setting in an educational context to encourage motivation and achievement. To what extent are these criteria present in goal-setting frameworks as employed in the classroom?

\section{An alternative to SMART}

Analysing the use of SMART against Zimmerman's (2008) eight criteria is problematic, both because of the variable nature of the SMART construct and its manner of use (Wade 2009). Jones and Duckett (2004), for example, advocate using 
SMART targets as a way of achieving longer-term goals, referring to evidence from case studies from further education colleges in the Learning and Skills Development Agency's 'Support for Success' programme. They highlight tutors and learners independently preparing for one-to-one tutorials; the importance of building a positive climate in which tutorials take place; learners setting their own long-term goals, shortterm targets and associated action points, with suggestions from tutors; tutors being encouraged to listen to learners; and agreements being made with an emphasis on students 'feeling good' about the process. On the other hand, SMART targets can be used in a more instrumental manner as part of normal classroom practice, with a greater emphasis on achievement for assessment (Chartered Institute of Educational Assessors 2010).

An alternative goal-setting and action-planning construct - the 'well-formed outcome' - has emerged from the field of neuro-linguistic programming (NLP) (Dilts and DeLozier 2000; Tosey and Mathison 2003). As will be argued, the well-formed outcome appears to meet Zimmerman's criteria and has at least two further advantages over the use of SMART targets.

Neuro-linguistic programming (NLP) is a communication and personal development discipline that has evolved from the mid-1970s, with its origins in the work of John Grinder and Richard Bandler at the University of California, Santa Cruz (Bandler and Grinder 1975a, 1975b; Grinder and Bandler 1976; Grinder et al. 1977). The rather mechanistic-sounding term 'neuro-linguistic programming' reflects their backgrounds: Grinder as a researcher in linguistics and Bandler as a student of mathematics and computing. 'Neuro' emphasises observable behaviour as a product of internal neurological (nervous system) processes, 'linguistic' highlights how analysis of spoken language can be revealing of beliefs, intentions, motives and 
thought processes, while 'programming', drawing upon cybernetics and computing terminology, refers to how internal processes and external actions can be organised to produce results (Robbie 1988; Dilts and DeLozier 2000, 849-855).

According to Tosey and Mathison (2009), in its origins NLP was influenced by intellectual developments and practices from the outcomes of the Macy Conferences, via the work of Gregory Bateson (e.g. Bateson 1973), and the work of the Palo Alto Mental Research Institute (e.g. Watzlawick et al. 1967). Craft (2001) considers that NLP reflects primarily constructivist principles, in terms of learning theory, while Day (2008) adds that NLP has behaviourist elements and is unusual among classroom practices in being, in some circumstances, radical constructivist (von Glasersfeld, 1995).

Since the 1970s, NLP has evolved to have many applications, in disciplines as diverse as accountancy and primary healthcare. In education, the potential of NLP for use by teachers has been recognised for some time (Tosey and Mathison 2003, 2010). The applications of NLP in classroom learning are wide-ranging, including: teachers better managing their own emotional states; educators more effectively crafting their communications to match a learner's preferences; and helping students maintain resourceful learning states, encouraging their creative problem-solving and their ability to experience problems from different points of view to better find solutions (e.g. Carey et al. 2009). NLP features in classroom guides for teachers (e.g. Smith 1998; Ginnis 2002; Churches and Terry 2007; Mahony 2007) and is gaining wide currency, for example, through the Fast Track teaching and leadership programme (Churches and West-Burnham 2008).

One of the key constructs in NLP, developed from observation and then tested and fine-tuned in practice, is that of the well-formed outcome (Dilts et al. 1980; Dilts 
and DeLozier, 2000, 1548-1550). Developers of NLP use the term 'outcome' rather than target or goal. This linguistic distinction is intentional; it shifts the emphasis from looking to the future for something one wishes to achieve, to the outcome being the unfolding of an action plan.

The term `well-formed' is influenced by Grinder's academic background in transformational linguistics, which at that time was concerned with the 'wellformedness' of linguistic constructions (Grinder and Elgin 1973). As adopted in NLP in relation to goal-setting, outcomes are considered to be 'well formed' when they meet at least five criteria. Various formulations of and acronyms for these criteria are found in NLP practitioner sources (e.g. Dilts and DeLozier 2000). Here we adopt the framework used by one of us (TD) in educational practice, which employs the mnemonic POWER to denote the following five elements:

P: The outcome is stated in the positive, as moving toward something the student wishes to have, rather than as moving away from something the student does not wish to have. This is based on the premise that thinking about what one does not wish to have will automatically bring the unwanted state to mind, rather than the 'wished for' state. So, for example, rather than saying the negative form 'I don't want to be stressed and confused at the beginning of the exam', the positive form might be 'I want to be calm and clear-headed at the beginning of the exam', so evoking the state the student seeks to achieve not the one they wish to leave behind.

O: The student's own role in making the outcome happen. The outcome needs to be something that the student makes happen as a result of their own actions, rather than being dependent solely or largely on the activities of others. For example, if preparing for an examination, they need to state the outcome in terms of what they 
will do, rather than what they might expect the teacher or other people to do (although their strategy might involve actions to help enlist the support of other people).

W: What specifically? This includes the student making an assessment of their starting point and their own (and others') actions as the student moves toward the outcome, plus the resources (time, physical resources, and so on) that are likely to be required in order to do so.

E: What evidence will the student have that reveals that they are making progress towards their outcome, and then, that they have achieved it? NLP is concerned with sensory-based evidence. What might the student see, hear, feel, taste or smell to know that they are reaching their outcome? This element of the POWER heuristic can be highly effective at encouraging the individual to mentally rehearse the experience of moving towards their outcome, and finally achieving it. For example, if they were considering preparing for an exam, what sensory-based evidence would reveal that they were being successful? Visual evidence might be the existence of a tidy desktop, annotations around their class notes, practice questions they had answered and had marked, and so on. Kinaesthetic evidence (concerning feelings and emotions) might be sensations of wellbeing and calmness, expressed in sensoryspecific terms. Such mental rehearsal can evoke sensory impressions that are more powerfully motivating than detached, abstract notions of 'what it takes to succeed' expressed in more conventional terms.

R: The fifth element of the well-formed outcome refers to relationship and entails what is called in NLP an 'ecology' check. 'Ecology' here refers, in the personal domain, to the effect that moving towards reaching an outcome has on the student's relationship with other people, and indeed, the relationship between different 'parts' of the student's own psyche. Having set an outcome, the student is 
encouraged to make an 'internal check' that the decision 'feels right'. Careful exploration of any uncomfortable feelings or confused thoughts often reveals factors that might prevent them achieving their outcome. Such factors could include other demands on their time (such as part-time paid work) or conflicts that might arise if seeking to achieve their outcome runs counter to expectations of their family or peers. Awareness of such barriers presents an opportunity for creative problem-solving and perhaps readjustment of intended outcomes. At the very least, it reveals issues that would have sabotaged the student achieving their outcomes in any case.

The outcome needs to be sufficiently significant so as to be motivating but not so large as to be overwhelming. Such a balance accords with recommended practice in setting targets with students; that targets should be realistic yet stretch the student so that he or she can achieve what was previously just out of reach (Flecknoe 2001; Martinez 2001).

There is some research evidence in favour of well-formed outcomes. Researchers at the Yale Child Study Center regarded using well-formed outcomes with students, and nurturing their 'future-orientation' (a positive attitude about themselves as successful learners and as contributing members of society), as key elements in a well-rounded social and emotional development programme (Ben-Avie et al. 2003). They associated these two practices with helping to enhance maths and science scores among middle school students.

\section{Well-formed outcomes in the light of goal-setting theory and research}

The well-formed outcomes framework, with its emphasis on positive orientation, accords well with the empirical findings of achievement goal research reviewed 
above, which suggest that 'orientation towards' goals are preferable to 'avoidance' goals, regardless of whether they are mastery- or performance-orientated. Regarding distinctions between mastery- and performance-orientations, as with Zimmerman's (2008) eighth criterion for setting goals, it seems likely that the context in which goals are set, and the interpretation by an individual as to whether a goal is mastery- or performance-orientated within their cluster of personal constructs, confounds the search for obvious associations. Indeed, it is likely that both mastery- and performance-orientations exist at one and the same time, in individuals and in classroom cultures (Pintrich 2000; McGregor and Elliot 2002).

The well-formed outcomes framework appears to meet at least four of Zimmerman's first six criteria (specific, congruent, challenging and self-generated), and encourages the other two (proximity in time and being hierarchical) through the 'nesting' or hierarchical arrangement of outcomes over different time scales. For Zimmerman's seventh criterion (degree of conscious awareness), NLP practitioners acknowledge the power of automaticity and consider that setting well-formed outcomes operates on both conscious and unconscious levels. For Zimmerman's eighth criterion, depending on an individual's preferences, well-formed outcomes could be either process or performance goals.

An additional feature of NLP's well-formed outcome is the incorporation of sensory-rich mental rehearsal. There is evidence from sport and other performance activities that positive mental rehearsal has demonstrable effects on enhancing performance (Woolfolk et al. 1985; Suinn 1997; Nordin and Cumming 2005). In sport, mental rehearsal is commonly called 'mental imagery' although it goes well beyond visualisation alone, being multi-sensory and often accompanied by activities such as self-talk and practised relaxation (Suinn 1997; Hale 1998; Holmes and Collins 
2001; Hale et al. 2005). Any and all such elements can also apply in the use of mental rehearsal as employed by NLP practitioners. Hale (1998, p4) defines mental imagery as 'a method of using all the senses to create or re-create an experience in the mind.' It can involve five primary senses - sight, sound, touch, smell and taste - as well as actions, thoughts, feelings and emotions.

The intention of mental rehearsal is to create, or recreate, key aspects of a mental/physical performance. Doing so, in a structured manner, has many potential benefits. It is likely to encourage the internalisation of extrinsic motivation (engaging in an activity for reasons other than it being inherently interesting or enjoyable). Such internalisation is associated with a greater likelihood of the student feeling in control and having a sense of ownership in achieving the outcome (Deci and Ryan 2000).

Mental rehearsal has long been a key element employed by successful Olympic teams (Suinn 1997). The benefits of mental rehearsal extend beyond physical skill and performance per se, but include qualities such as strengthening commitment, confidence and concentration, and enhancing the ability to beneficially control emotional state (Hale 1998; Hale et al. 2005). Such attributes clearly have relevance to learning in the classroom and elsewhere, not just applied to performance in sport.

A formal, analytical comparison between POWER and SMART is problematic because the SMART framework is variable in both its construct and its use (see, for example, Wade 2009). However, our discussion suggests that the construct of wellformed outcomes has a stronger and more explicit correspondence with current evidence and recommended practice emerging from theorising and research on selfregulated learning, achievement goal theory and mental rehearsal. 
The outcome-setting framework encourages personal exploration of thoughts and feelings. The construct of well-formed outcomes contains two key elements that can contribute to better target-setting and action-planning; namely, the encouragement of mental rehearsal, with an emphasis on sensory-based evidence in doing so, and an 'ecology' check on the likelihood of a given outcome being achievable. Target- or goal-setting using the SMART framework (specific, measurable, achievable or agreed-upon, realistic and time-based) could involve the exploration of potential obstacles (as in the 'ecology' check), and could explore feelings and emotions, but in many cases it does not (Blandford 1997; Flecknoe 2001; Martinez 2001).

\section{A practice-based vignette}

This article focuses on learning targets, action planning and their negotiation by student and teacher/tutor. Of course, such practice cannot be separated from the wider context of the learning culture in which it takes place, the power relationship between the two participants, and the nature of the learning contract between them. NLP favours a 'co-learner' contract between student and teacher, which aligns well with its fundamentally radical constructivist nature. In its purest form, the well-formed outcome framework has the student devising their own goals or targets. The reality in a secondary school or further education context is that this needs to be done within the context of priorities set by the curriculum and in relation to forms of assessment. Nevertheless, students' concerns are a good starting point, particularly if students are to be genuinely empowered and their learning is to be personalised.

A vignette is provided to show how the POWER model can be applied in context. The vignette is based on the actual stated outcome of a female Year 12 ASlevel Biology student. The outcome was captured as part of mixed-methods classroom 
research carried out by one of the authors with two AS-level classes in a 13-18 mixedgender college in the UK (Day 2008). The author was not the student's Biology tutor nor did he conduct a tutorial with this particular student. Rather, the vignette is an idealised account of how such a tutorial might be run based on best practice from that author's more than 8 years' experience as a Biology tutor using the well-formed outcomes framework with sixth form students and with mature students on a university open-access course. The student's outcome was set in March prior to the student taking AS-level examinations in June. The Biology tutor would be expected to see the student at least once more, several weeks before the examination, at a further tutorial meeting to discuss the student's progress towards the outcome (although the tutor might also discuss the outcome with the student one-to-one, informally, during class activities):

The student comes to a meeting with her Biology tutor bringing the following outcome (one of three she has set for herself this term, and the one she has prioritised for this meeting): 'My outcome is feeling confident entering the exam room, knowing I have revised as well as I can to achieve the highest grade I can realistically achieve.'

This outcome meets the first two POWER criteria: it is stated positively and the student's own role is clearly indicated. The next part of the one-to-one interaction considers the evidence that the student will experience to know that she has met her outcome (note: the elements of the POWER model do not have to follow the order indicated by the mnemonic, provided the first two criteria are met). The student describes the thoughts and feelings she will experience when she meets her outcome. What does that feel like? What thoughts are going through her head? What is she saying to herself? What does she see and hear in her surroundings? This rich description of the experience of meeting the outcome is key to encouraging effective 
mental rehearsal. It is likely to involve descriptions of 'internal' experience but might include 'external' impressions as well. As well as the description of the experience on entering the exam room, it might involve her describing the experience of reading the question paper and beginning to write the answers, and/or how it feels when she finally reads the printout that shows the exam grade she has achieved. In completing this part of the process the student usually becomes energised, having practised what it is like to experience her intended outcome.

Now the student considers the Relationship part of the model through her response to a question such as: 'If you could have this outcome, would you take it?' The teacher looks for signs of incongruence, in case the student is not wholeheartedly behind gaining her outcome. Incongruence can be indicated by a sudden shift in body language, or verbal signals/signs such as sighing, which may indicate a change from positive to uncertain. Gently exploring what lies behind such a shift is likely to reveal issues that might prevent the student from reaching her outcome. Dealing with such issues may move the dialogue seamlessly into the 'What specifically' part of the POWER model. Another possibility is that the intended outcome was unrealistic, and that the student needs to temper her high expectations. It could be that the student finds she needs to rephrase her outcome, fine-tuning the original one, or perhaps splitting it into two or more new outcomes of smaller size. The above student's intended outcome is large and, through questioning and discussion, it would be broken down into smaller outcomes and associated actions over different time scales.

There can be value in exploring the Relationship part of the model before moving onto the 'What specifically'. Doing so can prevent wasting time on an outcome that is not highly motivating or is based on wishful thinking and is unrealistic. Whether the 'What specifically' comes after or before the Relationship 
check, the 'What specifically' is powered by the experience of the earlier mental rehearsal in meeting the outcome. The 'What specifically' is the detailed actionplanning stage. It is student-focussed - hence personalised - and is informed by all the stages that have come before. For a student engaged in revision and examinationpreparation, the 'What specifically' can be wide ranging, including elements such as, choosing and creating an appropriate work environment, planning the best times of day to revise, checking progress, enlisting the help of others, and so on, as well as specific revision strategies aligned with subject matter, forms of assessment and an individual's learning preferences. Specifics can be revealed by highlighting key elements of the student's stated outcome, much as they might do in responding to an essay title: 'My outcome is to feel confident entering the exam room, knowing I have revised as well as I can to achieve the highest grade I can realistically achieve.'

Questions such as, 'What would you need to do beforehand to feel confident as you entered the exam room?', 'How would you know you had revised as well as you could?', and 'What exam grade do you think you can realistically achieve?' reveal the specific requirements for moving forward to meet the outcome and act as a check on how realistic it is to do so.

Goal-setting and action-planning using NLP's well-formed outcomes framework can be carried out deftly, taking perhaps fifteen minutes with a given student for a large outcome. The value in doing so is great if it increases the likelihood of the student achieving their self-set or negotiated learning outcome.

\section{Using well-formed outcomes in practice: further considerations}


Two key concerns teachers/tutors might have about the use of well-formed outcomes are: Do I have the time for this? And aren't we getting into feelings and emotional territory that I'm ill equipped to deal with?

In answer to the first question, assuming that setting learning targets is a priority, and that time is properly allocated for this one-to-one process, then incorporating well-formed outcome concepts should not unduly lengthen the process. Like developing any new capability, incorporating well-formedness criteria may be time-consuming initially but can soon be integrated into practice. The potential benefits of doing so are that student becomes more strongly engaged in the targetsetting and action-planning process, and the target becomes more realisable, or is modified to make it more realisable.

In answer to the second question, if affective aspects are important in student's learning it seems reasonable to suppose that they should be reflected in the targetsetting and action-planning process. At such times the focus of the staff-student interaction is on practical issues. The staff member is not expected to be an emotional counsellor, trained to deal with a student's deep distress and equipped to help them explore deep-seated emotional issues. If a student's personal issue is impacting on their learning and wellbeing, then it seems reasonable that the teacher/tutor should be at least be aware that this lies in the background. It does not mean that the staff member themselves is responsible for resolving the issue, or knowing specifically what it is. At the very least, they can encourage and support the student to seek and gain assistance elsewhere. In any case, failing to deal with, or at least acknowledge, an underlying issue may undermine the target-setting and action-planning process.

As we have seen, the POWER framework for outcome-setting is intended to be part of a negotiated dialogue between student and staff member that assists the 
student to define learning goals and move towards achieving them. It complements, and can be integrated into, other established frameworks for doing so, such as the GROW model ${ }^{1}$ used in coaching, developed by Whitmore (1996), which is currently advocated by the Centre for the Use of Research and Evidence in Education (CUREE, 2010) and used with both students and staff in some schools. Churches and Terry (2007) recommend employing an NLP-influenced SMART framework (specific, with milestones, framed 'as happening now', results-orientated with an emphasis on sensory-based evidence, and time-based) with the addition of further NLP elements using the mnemonic PURE (the outcome is positively framed, under the individual's control, of the right size, and ecological).

Setting an outcome and planning action to achieve it are worth little unless progress towards the outcome is monitored (by the student themselves and the staff member) and feedback given and acted upon. Here again, NLP offers a useful framework - the 'three steps to success' model (Day 2008) - as depicted in Figure 1.

\section{Insert Figure 1}

Using the 'three steps to success' framework, setting a well-formed outcome can be likened to steering a course in a sailing vessel. A destination is decided upon and a course towards it set, but wind, weather, ocean currents and other factors affect progress. At regular intervals the wise navigator takes stock of their location, considers how they wish to proceed, and whether or not they still intend to steer to the original destination or decide on another one. So it is with outcome-setting. Seen this way, well-formed outcomes are provisional. 
Applying the 'three steps to success' framework, a well-formed outcome is set (step one). In moving towards their outcome the student becomes aware of feedback (from their teacher, other people that influence their progression towards the outcome, their own reactions to what is happening, and so on). Sensory acuity (step two) is concerned with heightened awareness of feedback, both internal (within the individual) and external (from the individual's environment, especially other people). Is the feedback supporting the student's movement towards their outcome, or is it suggesting some reappraisal of outcome or the strategy of moving towards it? In progressing towards the outcome, flexibility of action (step three) in response to feedback is often crucial to success. The student may find that they need to alter their behaviour to achieve their outcome, or they might modify their outcome. The return arrows (feedback loops) acknowledge that awareness and actions from later steps feed forward to earlier steps, informing them and perhaps resulting in them being adjusted.

This 'three steps to success' model aligns with learning cycle frameworks suggested by experiential learning proponents, such as 'plan, act, review, and apply' (Kolb 1984; Gibbs 1988) or 'do, review, learn and apply’ (Dennison and Kirk 1990). Such reflective and action-planning practice is encouraged by researchers and teacher developers as appropriate for use by teachers and personal tutors when working with students (Bullock and Wikeley 2004; Watkins and Lodge 2007).

\section{Conclusion}

Despite the prominence of the use of learning goals or targets with students in secondary and further education, such as employed in personal development plans (PDPs) and personal learning plans (PLPs), and despite relevance to the 
personalisation agenda, there is a dearth of recent reported research on the conceptual robustness or effectiveness of heuristic goal-setting devices such as SMART. This article has reviewed relevant theory and research, highlighting Zimmerman's (2008) eight criteria. It has presented 'well-formed outcomes' as a framework that may have the potential to offer a more rigorous, holistic and research-informed approach to target- or goal-setting and action planning than SMART targets, given its more explicit fit with Zimmerman's criteria . Using well-formed outcomes gives the learner the opportunity to choose (or at least negotiate) their own outcomes, check how realistic they are, and through mental rehearsal harness sensory-based evidence along the path to reaching them. Given the lack of recent empirical work on common goalsetting practices in the classroom, and evaluation of their effectiveness, it is pertinent to underline the need for further research in these areas.

${ }^{1}$ The GROW acronym stands for G (establishing the goal), R (examining the current reality of the situation), $\mathrm{O}$ (considering the available options) and $\mathrm{W}$ (confirming the will to act and deciding what action to take). 
References

Anderman, E.M. and Wolters, C.A. 2006. Goals, values and affect: Influences on student motivation. In Handbook of Educational Psychology, 2nd ed., ed. P.A. Alexander and P.H. Winne, 369-389. Mahwah, New Jersey: Lawrence Erlbaum Associates.

Bandler, R. and Grinder, J. 1975a. The Structure of Magic, Volume I: A Book about Language and Therapy. Palo Alto, California: Science and Behaviour Books.

Bandler, R. and Grinder, J. 1975b. Patterns of the Hypnotic Techniques of Milton H. Erickson, MD. Cupertino, California: Meta Publications.

Bandura, A. 1986. Social Foundations of Thought and Action: A Social Cognitive Theory. Englewood Cliffs, New Jersey: Prentice Hall.

Bandura, A. 1997. Self-Efficacy: The Exercise of Control. New York: Freeman.

Bateson, G. 1973. Steps to an Ecology of Mind: Collected Essays in Anthropology, Psychiatry, Evolution and Epistemology. London: Paladin, Granada.

Ben-Avie, M., Haynes, N.M., White, J., Ensign, J., Steinfeld, T.R., Sartin, L.D. and Squires, D.A. 2003. Youth Development and Student Learning in Math and Science. In How Social and Emotional Development Add Up: Getting Results in Math and Science Education, ed. H.M. Haynes, M. and J. Ensign, 9-35. New York: Teachers College Press.

Blakemore, S.-J. and Frith, U. 2005. The Learning Brain. Oxford: Blackwell Publishing.

Blandford, S. 1997. Middle Management in Schools. London: Financial Times.

Bostic St. Clair, C. and Grinder, J. 2001. Whispering In The Wind. Scotts Valley, California: $\mathrm{J}$ and $\mathrm{C}$ Enterprises.

Broadfoot, P. (1988). Records of achievement: report of the national evaluation of pilot schemes. London: HMSO.

Bullock, K., Harris, A and Jamieson, I. 1996. Personal development plans and equal opportunities. Educational Research 38, no. 1: 21-35.

Bullock, K. and Jamieson, I. 1995. The effect of personal development planning on attitudes, behaviour and understanding. Educational Studies 21, no. 3: 307321.

Bullock, K. and Jamieson, I. 1998. The effectiveness of personal development planning. The Curriculum Journal 9, no.1: 63-77.

Bullock, K. and Wikeley, F. 1999. Improving learning in Year 9: making use of personal learning plans. Educational Studies 25, no. 1: 19-33.

Bullock, K. and Wikeley, F. 2004. Whose Learning? The Role of the Personal Tutor. Maidenhead, Berkshire: Open University Press.

Bullock, K. and Wikeley, F. 2008. Every child should have one: what it means to be a learning guide. Improving Schools, 11, no. 1: 49- 60.

Carey, J., Churches, R., Hutchinson, G., Jones, J. and Tosey, P. 2009. Neurolinguistic programming and learning: teacher case studies on the impact of NLP in education, Reading: CfBT Education Trust. Available online at http://www.cfbt.com/evidenceforeducation/pdf/5.NLP_(40pp)_FINAL(W).pdf (accessed 7 June 2010)

Chartered Institute of Educational Assessors. 2010. Target setting. Coventry: The Chartered Institute of Educational Assessors. Available online at 
http://www.ciea.org.uk/student_member_area/resources/first_steps_in_assess ment/target_setting.aspx (accessed 12 July 2010)

Churches, R. and Terry, R. 2007. NLP for Teachers: How to be a Highly Effective Teacher. Carmarthen: Crown House Publishing.

Churches, R. and West-Burnham, J. 2008. Leading learning through relationships: the implications of neuro-linguistic programming for personalisation and the Children's Agenda in England. A paper presented at The First International Neuro-Linguistic Programming Research Conference, 5 July 2008, Guildford, Surrey: School of Management, University of Surrey.

Claxton, G. 1999. Wise-Up: The Challenge of Lifelong Learning. New York: Bloomsbury.

Claxton, G. 2005. The Wayward Mind. London: Little, Brown.

Claxton, G. 2006. Learning to Learn: The Fourth Generation - Making Sense of Personalised Learning. Bristol: TLO.

Craft, A. 2001, Neuro-linguistic Programming and learning theory. The Curriculum Journal 12, no. 1: 125-136.

CUREE, 2010. Other mentoring and coaching resources. Coventry: Centre for the Use of Research and Evidence in Education. Available online at http://www.curee-paccts.com/mentoring-and-coaching/other-mentoring-andcoaching-resources (accessed 30 March 2010)

Day, T. R. (2008). A study of a small-scale classroom intervention that uses an adapted neuro-linguistic programming (NLP) modelling approach. Doctoral thesis. Bath: Department of Education, University of Bath.

Deci, E.L. and Ryan, R.M. 1985. Intrinsic Motivation and Self-Determination in Human Behavior. New York: Plenum.

Dennison, B. and Kirk, R. 1990. Do Review Learn Apply: a simple guide to experiential learning. Oxford: Blackwell.

Department for Children, Schools and Families. 2008. Personalised learning - A practical guide. Annesley, Nottingham: DCSF Publications.

Dilts, R. 1998. Modeling with NLP. Capitola, California: Meta Publications.

Dilts, R. and DeLozier, J. 2000. Encyclopedia of Systemic NLP and NLP New Coding. Scotts Valley, California: NLP University Press.

Dilts, R., Grinder, J., Bandler, R. and DeLozier, J. 1980. Neuro-Linguistic Programming: The Study of the Structure of Subjective Experience. Volume 1. Cupertino, California: Meta Publications.

Doran, G.T. 1981. There's a S.M.A.R.T. way to write management's goals and objectives. Management Review 70, no. 11: 35-36.

Drucker, P. F. 1954. The Practice of Management. New York: Harper Brothers.

Fielding, M. 1999. Target setting, policy pathology and student perspectives: learning to labour in new times. Cambridge Journal of Education 29, no. 2: 277-287.

Fitzsimons, G.M. and Bargh, J.A. 2004. Automatic self-regulation. In Handbook of self-regulation: Research, theory, and applications, ed. R.F. Baumeister and K.D. Vohs, 151-170. New York: Guilford Press.

Flecknoe, M. 2001. Target setting: will it help to raise achievement? Educational Management, Administration and Leadership 29, no. 2: 217-228.

Gibbs, G. 1988. Learning by Doing: A guide to teaching and learning methods. London: Further Education Unit.

Ginnis, P. 2002. The Teacher's Toolkit. Carmarthen: Crown House Publishing.

Gordon, D. and Dawes, G. 2005. Expanding Your World: Modeling the Structure of Experience. Tucson, Arizona: Desert Rain. 
Grinder, J. and Bandler, R. 1976. The Structure of Magic, Volume II. Palo Alto, California: Science and Behaviour Books.

Grinder, J., DeLozier, J. and Bandler, R. 1977. Patterns of the Hypnotic Techniques of Milton H. Erickson, MD, Volume II. Cupertino, California: Meta Publications.

Grinder, J. and Elgin, S. 1973. A Guide to Transformational Grammar. New York: Holt, Rinehart and Winston.

Hale, B.D. 1998. Imagery training: A guide for sports coaches and performers. Leeds, UK: National Coaching Foundation.

Hale, B.D., Seiser, L., McGuire, E.J. and Weinrich, E. 2005. Mental Imagery. In Applying Sport Psychology: Four Perspectives, ed. J. Taylor, J. and G.S. Wilson, 117-135. Champaign, Illinois: Human Kinetics.

Holmes, P.S. and Collins, D.J. 2001. The PETTLEP approach to motor imagery: A functional equivalence model for sport psychologists. Journal of Applied Sport Psychology 13: 115-121.

James, M., Black, P., McCormick, R., Pedder, D. and Wiliam, D. 2006. Learning How to Learn, in Classrooms, Schools and Networks: aims, design and analysis. Research Papers in Education 21, no. 2: 101-118.

Jones, C.A. and Duckett, I. 2004. Tutorials and target-setting in the effective delivery of vocational A-levels. London: Learning and Skills Network.

Kolb, D.A. 1984. Experiential Learning: Experience as a Source of Learning and Development. Englewood Cliffs, NJ: Prentice Hall.

Locke, E.A. and Latham, G.P. 2002. Building a practically useful theory of goal setting and task motivation: A 35-year odyssey. American Psychologist 57, no. 9: 705-717.

Mahony, T. 2007. Making Your Words Work: Using NLP to Improve Communication, Learning and Behaviour. Carmarthen: Crown House Publishing.

Martinez, P. 2001. Great Expectations: Setting Targets for Students. London: Learning and Skills Development Agency.

McGregor, H.A. and Elliott, A.J. 2002. Achievement goals as predictors of achievement-relevant processes prior to task engagement. Journal of Educational Psychology 94, no. 2: 381-395.

McNeil, F. 2009. Learning with the Brain in Mind. London: Sage.

Merson, M. 1992. The four ages of TVEI: a review of policy. British Journal of Education and Work 5, no. 2: 5-18.

Midgley, C., Kaplan, A., Middleton, M., Maehr, M.L., Urdan, T., Anderman, L.H., Anderman, E. and Roeser, R. 1998. The development and validation of scales assessing students' achievement goal orientations. Contemporary Educational Psychology 23: 113-131.

Midgley, C., Kaplan, A. and Middleton, M. 2001. Performance-approach goals: Good for what, for whom, under what circumstances, and at what cost? Journal of Educational Psychology 93, no. 1: 77-86.

Murayama, K. and Elliot, A.J. 2009. The Joint Influence of Personal Achievement Goals and Classroom Goal Structures on Achievement-Relevant Outcomes. Journal of Educational Psychology 101, no. 2: 432-447.

Nordin, S.M. and Cumming, J. 2005. More Than Meets the Eye: Investigating Imagery Type, Direction, and Outcome. The Sport Psychologist 19: 1-17.

Oxford English Dictionary. 1989, 2010. Oxford English Dictionary [on-line]. Second edition. Oxford: Clarendon Press. Available online at http://www.oed.com:80/Entry/79557 (accessed 19 December 2010) 
Pintrich, P. 2000. Multiple goals, multiple pathways: The role of goal orientation in learning and achievement. Journal of Educational Psychology 92, no. 3: 544555.

Posner, M. and Rothbart, M.K. 2007. Educating the Human Brain. New York: American Psychological Association.

Raia, A.P. 1965. Goal Setting and Self-Control: An Empirical Study. Journal of Management Studies 2, no. 1: 34-53.

Robbie, E. 1988. Neuro-linguistic programming. In Innovative Therapy in Britain, ed. J. Rowan, and W. Dryden, 251-279. Milton Keynes: Open University Press.

Ryan, R.M. and Deci, E.L. 2000. Intrinsic and Extrinsic Motivations: Classic Definitions and New Directions. Contemporary Educational Psychology 25: 54-67.

Schunk, D.H. 1989. Social cognitive theory and self-regulated learning. In Selfregulated learning and academic achievement: Theory, research and practice, ed. B.J. Zimmerman and D.H. Schunk, 83-110. New York: Springer-Verlag.

Smith, A. 1998. Accelerated Learning in Practice. Stafford: Network Educational Press.

Suinn, R.M. 1997. Mental Practice in Sport Psychology: Where Have We Been, Where Do We Go? Clinical Psychology: Science and Practice 4, no. 3: 189207.

Technical and Vocational Education Initiative. 1991. Flexible Learning: a framework for education and training in the skills decade. Sheffield: The Employment Department.

Tosey, P. and Mathison, J. 2003. Neuro-linguistic programming and learning theory: a response. The Curriculum Journal 14, no. 3: 371-388.

Tosey, P. and Mathison, J. 2009. NLP: a critical appreciation for managers and developers. Basingstoke: Palgrave Macmillan.

Tosey, P. and Mathison, J. 2010. Neuro-Linguistic Programming as an Innovation in Education and Teaching. Innovations in Education and Teaching International, 47 no. 3: 317-326

von Glasersfeld, E. 1995. Radical Constructivism: A Way of Knowing and Learning. London: Falmer Press.

Wade, D.T. 2009. Goal setting in rehabilitation: an overview of what, why and how. Clinical Rehabilitation 23: 291-295

Watkins, C., with Carnell, E., Lodge, C., Wagner, P. and Whalley, C. 2001. Learning about Learning enhances performance. School Improvement Network Research Matters No. 13. London: University of London, Institute of Education.

Watkins, C. and Lodge, C. 2007. Effective Learning in Classrooms. London: Paul Chapman.

Watts, A. 1992. Individual action planning: issues and strategies. British Journal of Education and Work 5, no. 1: 47-64.

Watts, A. 1993. Developing individual action-planning skills. British Journal of Education and Work 7, no. 2: 51-62.

Watzlawick, P., Beavin, J. H., and Jackson, D. D. 1967. Pragmatics of Human Communication. New York: W.W.Norton \& Co.

Whiteside, T. 1994 Tutoring and guidance post-16: the students' view. The Curriculum Journal 5, no. 3: 381-91.

Whitmore, J. (1996). Coaching for Performance: Growing People, Performance and Purpose. London: Nicholas Brealey. 
Wolters, C.A. 2004. Advancing achievement goal theory: Using goal structures and goal orientations to predict students' motivation, cognition, and achievement. Journal of Educational Psychology 96, no. 2: 236-250.

Woolfolk, R.L., Parrish, M.W. and Murphy, S.M. 1985. The Effects of Positive and Negative Imagery on Motor Skill Performance. Cognitive Therapy and Research 9, no. 3: 335-341.

Zimmerman, B.J. 2008. Goal setting: A key proactive source of academic selfregulation. In Motivation and Self-Regulated Learning, ed. D.H. Schunk and B.J. Zimmerman, 267-295. New York: Lawrence Erlbaum Associates. 


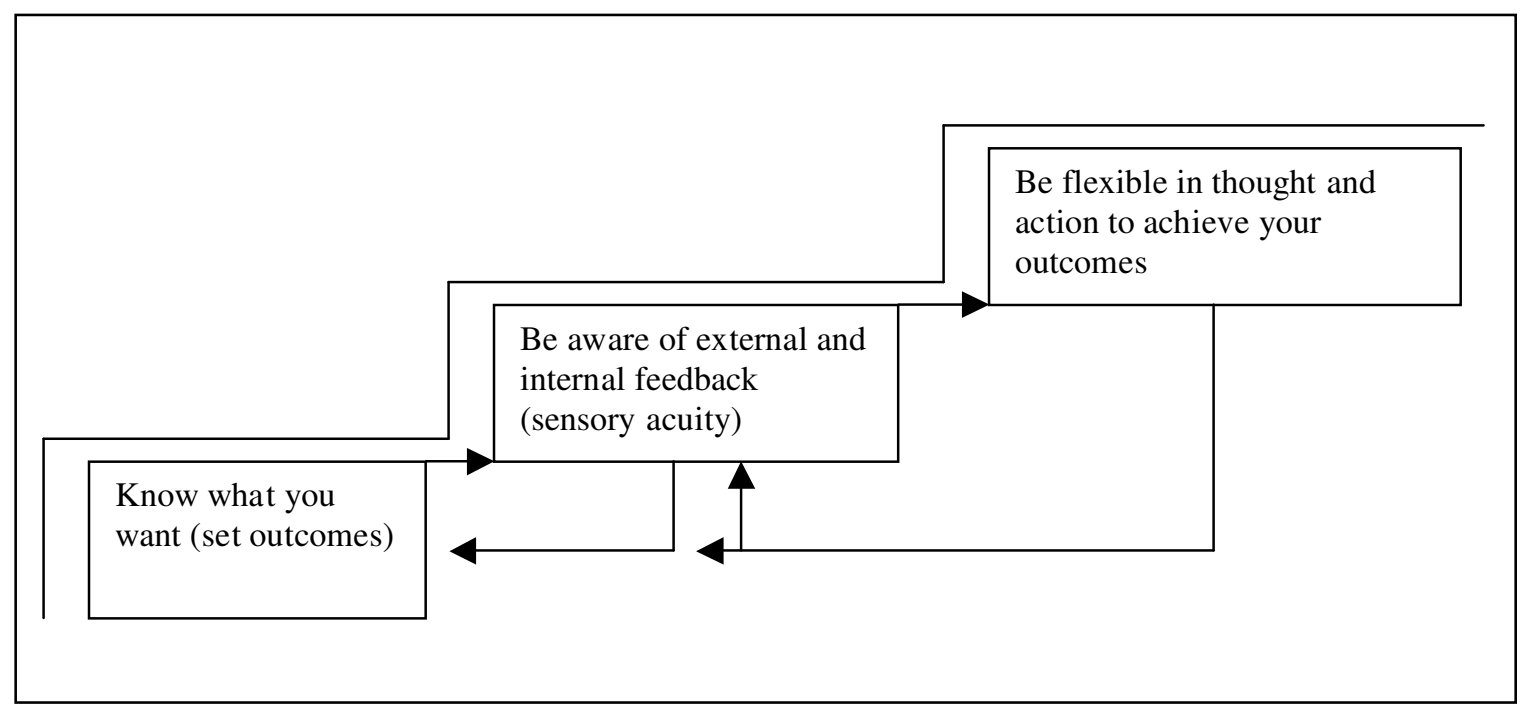

Figure 1. The 'three steps to success' framework (Day 2008) 